\title{
On the microstructure of tungsten disulfide films alloyed with carbon and nitrogen
}

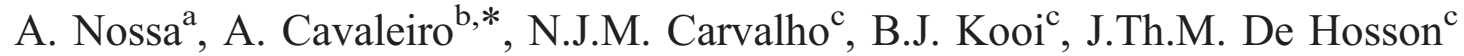 \\ ${ }^{a}$ Escola Superior de Tecnologia e Gestão, Instituto Politécnico da Guarda, Guarda, Portugal \\ ${ }^{\mathrm{b}}$ ICEMS, Departamento de Engenharia Mecânica, Faculdade de Ciências e Tecnologia, Universidade de Coimbra, Engenharia Mecnica-GEMS, \\ Polo II - Pinhal de Marrocos, 3030201, Coimbra, Portugal \\ ${ }^{\mathrm{c}}$ Department of Applied Physics, Materials Science Centre and Netherlands Institute for Metals Research, University of Groningen, The Netherlands
}

Received 27 February 2004; accepted in revised form 7 February 2005

Available online 22 April 2005

\begin{abstract}
This work aimed at studying the effect of a Ti interlayer and the alloying with carbon and nitrogen of W-S-C(N) films on the mechanical and tribological properties. The W-S-C and W-S-N films were deposited by r.f. magnetron reactive sputtering with $\mathrm{CH}_{4}$ or $\mathrm{N}_{2}$ as reactive gases and analysed by high resolution electron microscopy techniques. The hardness showed an improvement with the addition of the alloying element, which was attributed to the densification of the morphology, the decrease of the grain size, and the precipitation of new phases harder than $\mathrm{WS}_{2}$. The formation of either TiC or TiN at the interface between the Ti interlayer and the W-S-C(N) films promoted the enhancement of adhesion in the alloyed films. These improvements led to an enhanced tribological behaviour, in particularly the lowering of the wear coefficients.
\end{abstract}

(C) 2005 Elsevier B.V. All rights reserved.

PACS: $81.15 . \mathrm{Cd} ; 81.40 \mathrm{Pq}$

Keywords: Transmission electron microscopy (TEM); Nanostructures; Sputtering; Self-lubricating coatings

\section{Introduction}

The role of a lubricant is to prevent opposite surfaces from coming into close contact with each other, thereby preventing their mutual destruction. Liquid lubricants have been used to suppress or to limit the contact pressure, to reduce the friction and to facilitate sliding between solid bodies. Further, they allow the reduction of heating generated by friction. In many cases, the presence of liquid is neither possible nor recommended, or it can even be prohibited to avoid the contamination of the product which is in contact with. This is particularly true for vacuum environments, mechanisms where it is necessary to maintain very low tolerances, and applications in materials with incompatibility problems. In the manufacturing industry whenever two solids slide against each other deterrence of

\footnotetext{
* Corresponding author.

E-mail address: albano.cavaleiro@dem.uc.pt (A. Cavaleiro).
}

liquid lubricants is a great challenge. Examples are the diversity of components in engines, and even more importantly the vast range of materials processing operations like stamping or cutting. Consequently, the design and development of self-lubricating coatings became an attractive subject of applied research.

In the last three decades transition metal dichalcogeneides (TMDC) $\mathrm{MS}_{2}$, with $\mathrm{M}=\mathrm{Mo}$ and $\mathrm{W}$, have been used as selflubricating materials. In spite of $\mathrm{MoS}_{2}$ being more extensively studied, the $\mathrm{WS}_{2}$ has an improved oxidation resistance and thermal stability withstanding temperatures of about 50 $100{ }^{\circ} \mathrm{C}$ higher than the former. Moreover, $\mathrm{WO}_{3}$ is slightly more protective and provides a lower friction coefficient than $\mathrm{MoO}_{3}(0.2-0.3$ versus $0.5-0.6$, respectively) [1]. The main disadvantages of TMDC are their poor tribological properties in oxygen or moist environments [2-5] and the low load bearing capacity, which is due to the typical columnar morphologies [5-8]. All of this makes these coatings inappropriate for operation in environments under high 


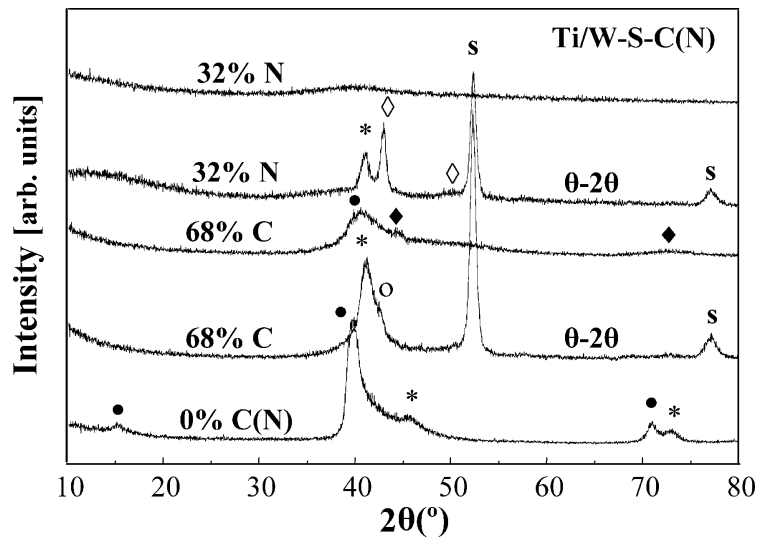

Fig. 1. XRD patterns obtained in glancing and $\theta-2 \theta$ modes of $\mathrm{Ti} / \mathrm{W}_{40} \mathrm{~S}_{60}$, $\mathrm{Ti} / \mathrm{W}_{17} \mathrm{~S}_{15} \mathrm{C}_{68}$ and $\mathrm{Ti} / \mathrm{W}_{34} \mathrm{~S}_{34} \mathrm{~N}_{32}$ coatings deposited with a Ti interlayer. (s=substrate; $\bullet=\mathrm{WS}_{2} ; *=\mathrm{Ti} ; \diamond=\mathrm{TiN} ; \mathrm{o}=\mathrm{TiC} ; \diamond=\mathrm{WC}$ phases).

contact load. Many different approaches have been tried to overcome these problems, including the introduction of metals or compounds whose objective is to produce dense microstructures and to increase the oxidation resistance, the mechanical behaviour and the tribological performance [912]. Promising results concerning industrial applications are expected for the $\mathrm{WS}_{2}$ films developed in our group, when they are alloyed with carbon or nitrogen [13]. In these studies the influence of several deposition conditions on the mechanical properties of W-S sputtered films with increasing $\mathrm{C}$ and $\mathrm{N}$ contents was investigated. Significant improvements on the hardness, adhesion and tribological behaviour were reached with $\mathrm{C}$ or $\mathrm{N}$ alloying which were correlated with the chemical composition and the structure of the films. However, no systematic analysis of the cross-sectional microstructure of the films was performed. This paper concentrates on an in-depth understanding of the microstructure of W-S sputtered films alloyed with increasing carbon and nitrogen contents, using high-resolution transmission and scanning electron microscopy techniques (HRTEM and HRSEM, respectively) as the principal tools. The objective is to shed some light on the understanding of the mechanical behaviour and tribological performance evaluated in previous research works [13-15]. In particularly the following points will be addressed:

- What is the relationship between the improvement of hardness and the microstructure?

- What is the role of the Ti interlayer, and how the alloying elements affect the adhesion of the films?
- What is the role played by the coating's microstructure on the tribological behaviour?

\section{Experimental details}

Ti/W-S-N and Ti/W-S-C coatings were deposited by r.f. magnetron sputtering using sintered $\mathrm{Ti}$ and $\mathrm{WS}_{2}(99.9 \%)$ targets with a diameter of $100 \mathrm{~mm}$ in a basic ESM 100 Edwards unit. The substrate to target distance was $65 \mathrm{~mm}$. The substrates used for microstructural analysis were either stainless steel (AISI 310) or alloy steel (AISI L1) and their surface was polished with a diamond paste of particle sizes down to $3 \mu \mathrm{m}$. Before deposition, the substrates were cleaned for $30 \mathrm{~min}$ by establishing the plasma close to the substrate electrode with a discharge power of $250 \mathrm{~W}(\sim 800$ $\mathrm{V})$. The ratio of the mass flow of the reactive gases $\left(\mathrm{N}_{2}\right.$ or $\mathrm{CH}_{4}$ ) and argon was within the range $0-25 \%$ and $0-10 \%$, respectively. The interlayer and the film were deposited with substrates in ground conditions. The discharge pressure and power for deposition of the interlayer were $1 \mathrm{~Pa}$ and $6.4 \mathrm{~W} /$ $\mathrm{cm}^{2}$, whereas for the film were $1 \mathrm{~Pa}$ and $5 \mathrm{~W} / \mathrm{cm}^{2}$, respectively. The total deposition time was kept constant at $75 \mathrm{~min}(15 \mathrm{~min}$ for Ti interlayer and $60 \mathrm{~min}$ for the W-S$\mathrm{N}$ or W-S-C films). The Ti interlayer thickness was approximately $700 \mathrm{~nm}$ while the remaining film was in a range of $1-3 \mu \mathrm{m}$.

High-resolution transmission and scanning electron microscopy were performed using a Jeol 4000 EX/II, operating at $400 \mathrm{kV}$, and a SEM XL30 microscope. The cross-sectional SEM observations were carried out on asdeposited fractured coated samples.

The specimen preparation for TEM analysis was performed according to a procedure developed in house [16]. Briefly, it consisted of cutting the coated samples in slices of $1.5 \mathrm{~mm}$ thick. Afterwards, two pieces were glued film-to-film and ground from both sides until an approximate thickness of $500 \mu \mathrm{m}$ was reached. Then, the laminate was glued on a copper ring of $3 \mathrm{~mm}$ diameter and the assembly was carefully polished until a thickness of about $20 \mu \mathrm{m}$. Ion milling with two guns in mirrored positions was used to further thin the sample. Subsequent thinning to electron transparency was performed using $4.0 \mathrm{kV}$ ion guns tilted $\left(3-8^{\circ}\right)$ with respect to the samples surface. The mechanical properties and the tribological behaviour of the $\mathrm{W}-\mathrm{S}-\mathrm{C}(\mathrm{N})$ sputtered films were evaluated previously $[13,14]$. The hardness was measured by depth sensing

Table 1

Mechanical and tribological properties of W-S and W-S-C(N) films

\begin{tabular}{|c|c|c|c|c|c|c|}
\hline \multirow[t]{2}{*}{ Film } & \multirow{2}{*}{$\begin{array}{l}\text { Adhesion } \\
{[\mathrm{N}]}\end{array}$} & \multirow{2}{*}{$\begin{array}{l}\text { Hardness } \\
{[\mathrm{GPa}]}\end{array}$} & \multicolumn{2}{|l|}{ Friction coefficient } & \multicolumn{2}{|c|}{ Wear coefficient $\left[\mathrm{m}^{3} / \mathrm{N} \mathrm{m}\right]$} \\
\hline & & & Moist air $\mathrm{RH}=60 \%$ & Nitrogen $\mathrm{RH}=20 \%$ & Moist air $\mathrm{RH}=60 \%$ & Nitrogen $\mathrm{RH}=20 \%$ \\
\hline $\mathrm{Ti} / \mathrm{W}_{35} \mathrm{~S}_{65}$ & 5.2 & 0.6 & 0.15 & 0.06 & $4.7 \times 10^{-14}$ & $7.7 \times 10^{-15}$ \\
\hline $\mathrm{Ti} / \mathrm{W}_{18} \mathrm{~S}_{18} \mathrm{C}_{64}$ & $>50$ & 5.4 & 0.20 & 0.07 & $1.5 \times 10^{-15}$ & $9.4 \times 10^{-16}$ \\
\hline $\mathrm{Ti} / \mathrm{W}_{33} \mathrm{~S}_{38} \mathrm{~N}_{29}$ & 36.6 & 4.6 & 0.35 & 0.05 & $1.6 \times 10^{-14}$ & $6.2 \times 10^{-17}$ \\
\hline
\end{tabular}


indentation with a maximum applied load of $20 \mathrm{mN}$. The critical load for adhesion (Lc) was assessed by scratchtesting, which was performed up to a maximum load of 50 $\mathrm{N}$. The Lc values were measured by analysing the failures events in the scratch track by optical microscopy. The wear and friction coefficients were determined from pin-on-disk testing, using a $10 \mathrm{~mm} \mathrm{L1}$ (AISI) steel ball sliding at a constant speed of $0.1 \mathrm{~m} / \mathrm{s}$ against the W-S-C(N) coated L1 (AISI) disks. The wear coefficient of the films was calculated by integrating the worn cross profile to the track perimeter $(\sim 63 \mathrm{~mm})$ and normalise it to the total sliding distance $(1000 \mathrm{~m})$ and applied load $(10 \mathrm{~N})$.

\section{Results}

\subsection{Summary of previous results}

The W-S-C(N) films were deposited with $\mathrm{C}$ and $\mathrm{N}$ contents up to 64 and 29 at.\%, respectively. From X-ray diffraction (XRD) and photoelectron spectroscopy (XPS) analysis, different type of bonds (W-S, W-C(N) and C-C) could be detected as a function of the chemical composition. In some cases (e.g. in $\mathrm{W}_{18} \mathrm{~S}_{18} \mathrm{C}_{64}$ ) these bonds were detected simultaneously, suggesting the formation of a composite structure involving sulphide, carbide/nitride and carbon phases [15]. The presence of the crystalline $2 \mathrm{H}-\mathrm{WS}_{2}$ phase in the unalloyed or low-alloy films was clearly identified. However, for higher $\mathrm{C}$ or $\mathrm{N}$ contents this phase was less well-defined, i.e. the diffraction peaks were attributed to a $\mathrm{W}$ compound difficult to index. The diffraction spectra suggested the following forms: $\beta$ $\mathrm{WC}_{1-x}, \mathrm{WC}$ and $\alpha-\mathrm{W}_{2} \mathrm{C}$. For the particular case of films with the highest $\mathrm{N}$ content, it was not possible to detect any crystalline feature in the XRD pattern, suggesting the existence of an amorphous structure (see Fig. 1).

An increase in hardness of more than one order of magnitude was reached whenever W-S film was alloyed

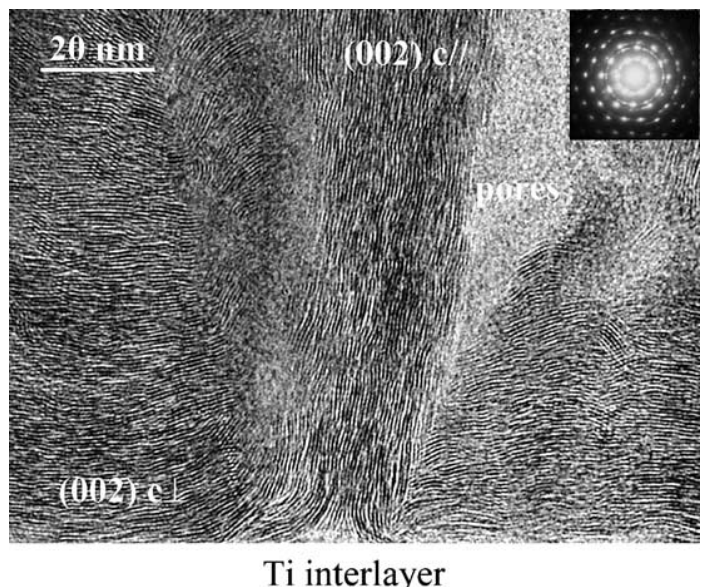

Fig. 2. Cross-sectional TEM micrograph of the $\mathrm{W}_{40} \mathrm{~S}_{60}$ film. The SAED pattern in the inset was taken from the middle of the films. a)

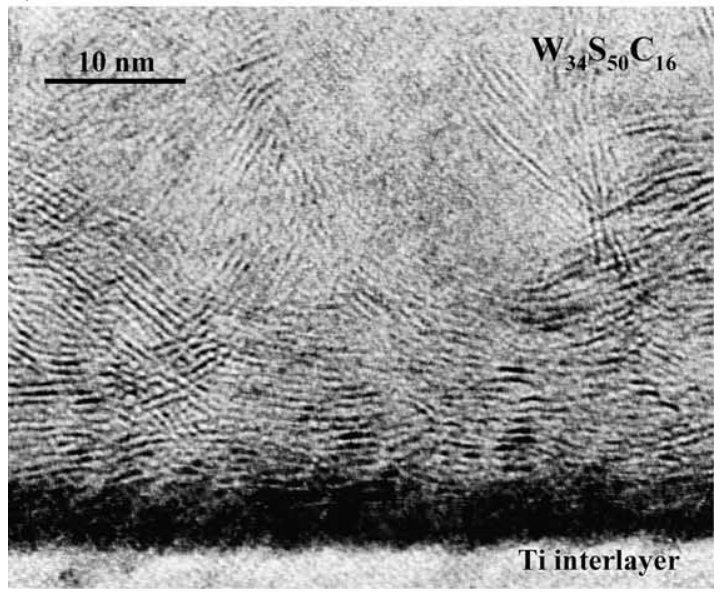

b)

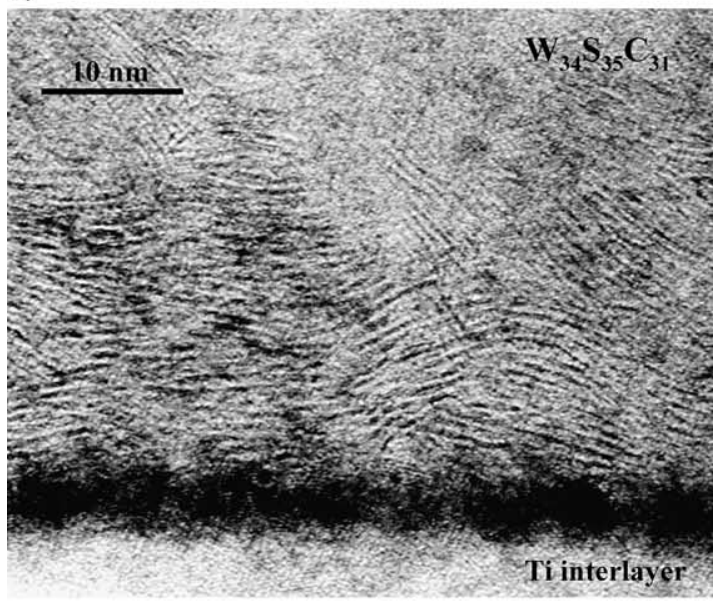

c)

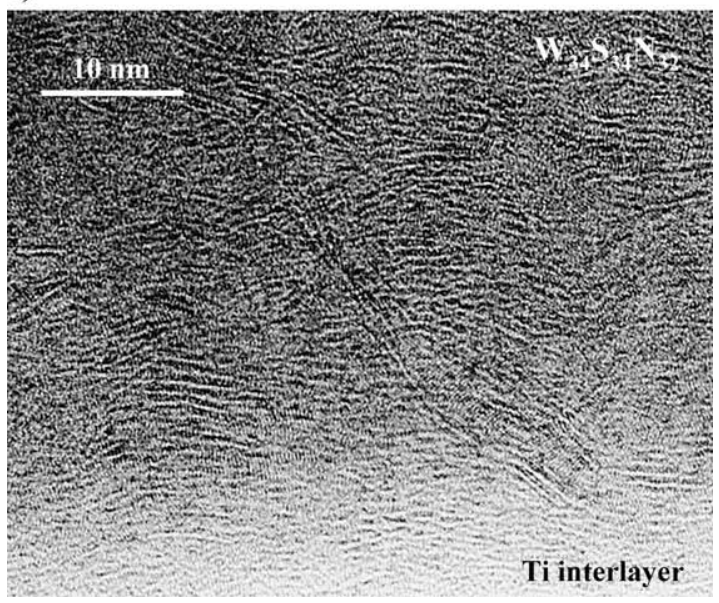

Fig. 3. Cross-sectional HRTEM micrographs of (a) $\mathrm{W}_{34} \mathrm{~S}_{50} \mathrm{C}_{16}$; (b) $\mathrm{W}_{34} \mathrm{~S}_{35} \mathrm{C}_{31}$; (c) $\mathrm{W}_{34} \mathrm{~S}_{34} \mathrm{~N}_{32}$ films. All micrographs were taken close to the interface between the film and the Ti interlayer.

with $\mathrm{C}$ or $\mathrm{N}$ (from 0.5 up to $6 \mathrm{GPa}$ ). All coatings showed that the critical load values were very reduced, not surpassing $5 \mathrm{~N}$, and independent of the alloying content. No relationship between the hardness and the scratch-test values could be established. In order to improve the 
adhesion of $\mathrm{W}-\mathrm{S}-\mathrm{C}(\mathrm{N})$ films, the deposition of a Ti interlayer was optimised, leading to an increase of the critical load to values over $50 \mathrm{~N}$ [13]. In this situation the presence of alloying elements increased the critical load values, being the improvement directly related to their content. The tribological performance was also improved with the $\mathrm{C}$ or $\mathrm{N}$ alloying. When testing in humid atmospheres and in relation to films without alloying elements, the progressive addition of $\mathrm{C}$ led to a decrease of the wear coefficient value down to more than one order of magnitude. However, no enhancement in the friction coefficient was observed. The lowest wear coefficient was reached for a coating with 64 at.\% of $\mathrm{C}$. The addition of $\mathrm{N}$ did not result in any advantage for the wear and friction coefficients over the base W-S films.

In the condition of testing in dry environments the Ccontaining films showed an improved tribological behaviour. The wear resistance increased progressively with increasing $\mathrm{C}$ contents, without any significant change in the friction coefficient. The main difference was observed for W-S-N films; In this case, the decrease in the wear coefficient reached two orders of magnitude with respect to the W-S film, keeping the friction coefficient also at a lower value. Table 1 summarizes, for the best performing $\mathrm{N}$ and $\mathrm{C}$ containing films the mechanical and tribological results obtained in these previous works [13,14], which are correlated to the base W-S films.

\subsection{Microstructural analysis}

Fig. 2 shows a cross-sectional TEM micrograph of the basal planes of the $\mathrm{WS}_{2}$ phase. The micrograph is from a region close to the interface between the Ti interlayer and the W-S film. In the first 5-50 $\mathrm{nm}$ the crystallites had a preferentially growth with their basal planes parallel to the interface, leading to the known type II structure [17,18]. Nevertheless, grains with the (002) plans normal to the interface (type I structure $[17,18]$ ) were occasionally detected. Further in the film thickness, it was observed that the grains displayed a random orientation.

The selected area electron diffraction (SAED) pattern shown in the inset of Fig. 2 corresponds to a zone in the middle of the film and shows several rings, allowing the identification of the $2 \mathrm{H}-\mathrm{WS}_{2}$ phase and a mixture of different oriented crystallites. When the W-S films were sputtered with increasing $\mathrm{C}$ and $\mathrm{N}$ contents the type II layers close to the interface decreased its predominance and also the (002) plans became more randomly oriented, as shown in Fig. 3. The crystallite size decreased accordingly and a randomly oriented nanostructure could be observed for films with the highest $\mathrm{C}$ atomic percent (see Fig. 4a). The SAED pattern of this film is shown in the inset displaying the diffuse diffraction rings due to the small grain size. Fig. $4 \mathrm{~b}$ shows the experimental rings from the insert and correlates them to those created from the standard values of several W$\mathrm{C}$ compounds. As can be observed there is a good agreement, in particular concerning the $\mathrm{W}_{2} \mathrm{C}$ and the $\mathrm{WC}_{1-\times}$ phases.

The structure of the films with the highest $\mathrm{N}$ content (>15 at.\%) consisted mainly of an amorphous phase, which is in accordance with the XRD studies. Even though, close to the interface, crystalline features were observed (e.g. film $\mathrm{W}_{34} \mathrm{~S}_{34} \mathrm{~N}_{32}$ on Fig. $3 \mathrm{c}$ ).

With the decreasing of the grain size an improvement of the density of the W-S-C(N) films was observed. Fig. 5 shows that the characteristic porous columnar type 1 morphology, according to the zone classification proposed by Thornton [19], of single W-S film becomes progressively denser up to the "featureless" glassy aspect with the highest alloying element content. a)

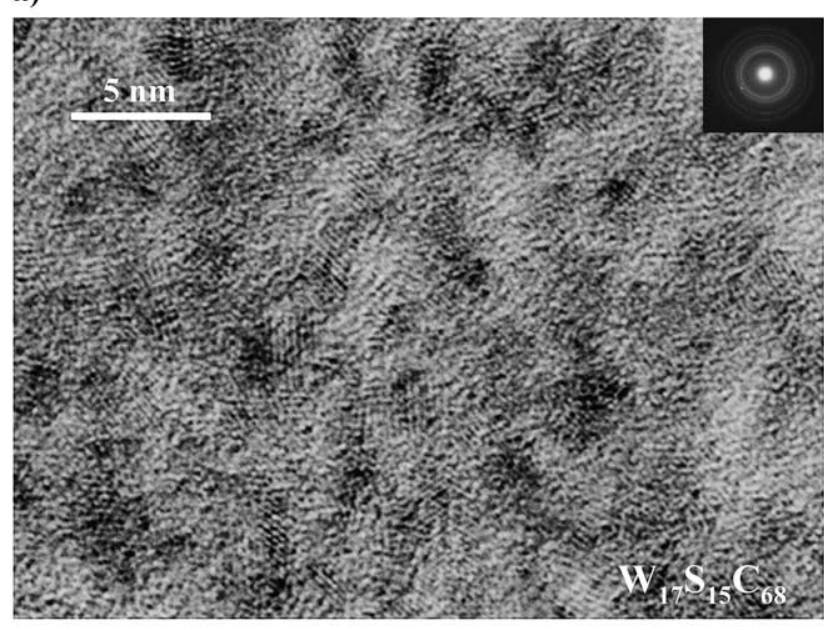

b)

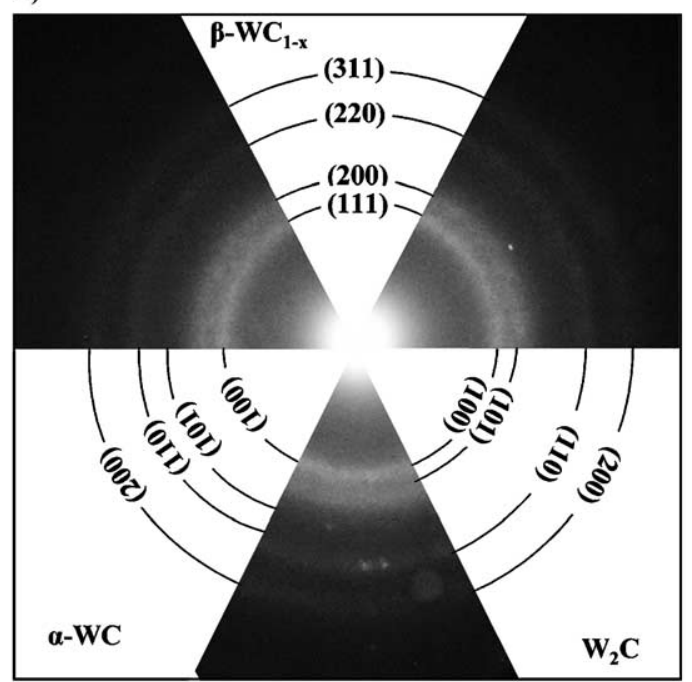

Fig. 4. (a) Cross-sectional TEM micrograph of W-S-C film deposited with the highest C content; (b) high magnification of the SAED inset of (a), superimposed with the standard schematic diffraction lines of several W-C compounds. 
The analysis of the interfacial region between the Ti interlayer and the W-S-C(N) films allows the identification of a transition region, where the direct measurement of the interplanar distance gives a value close to $0.265 \mathrm{~nm}$ (see Fig. 6). This value is similar to the interplanar distance of

a)

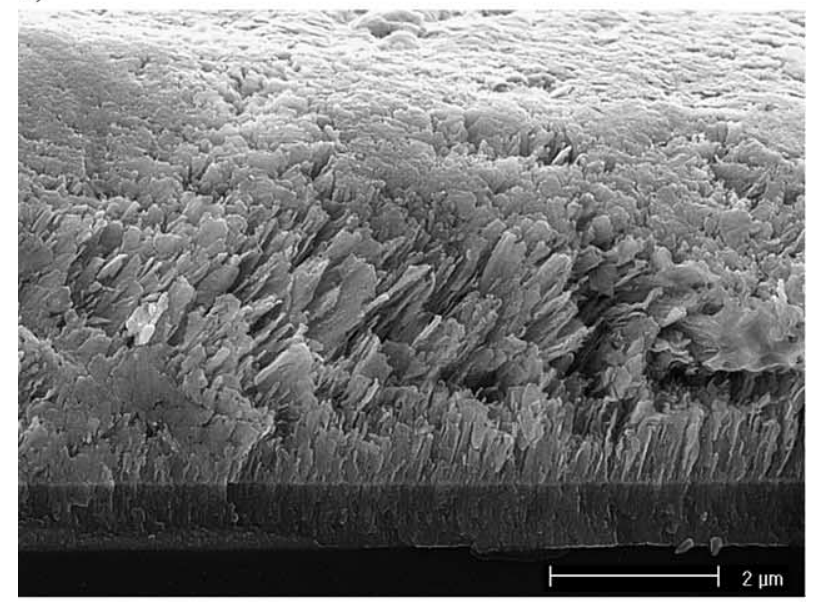

b)

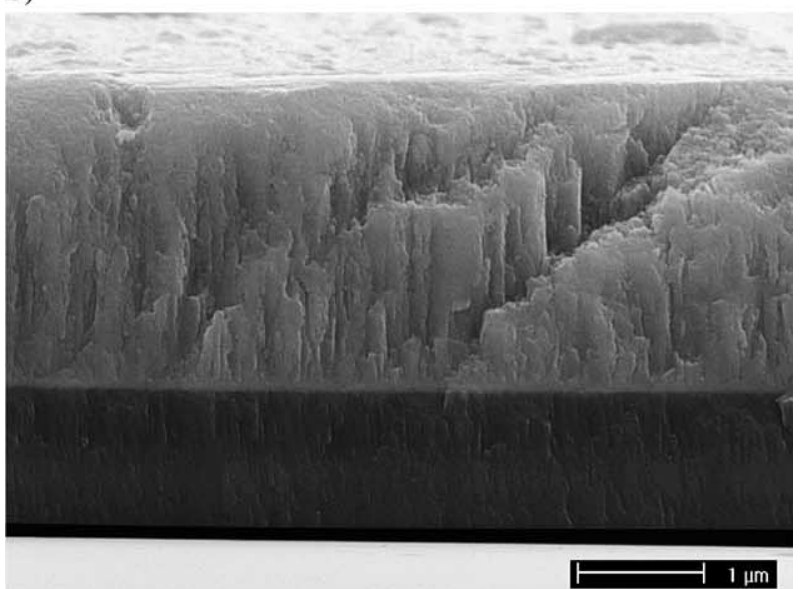

c)

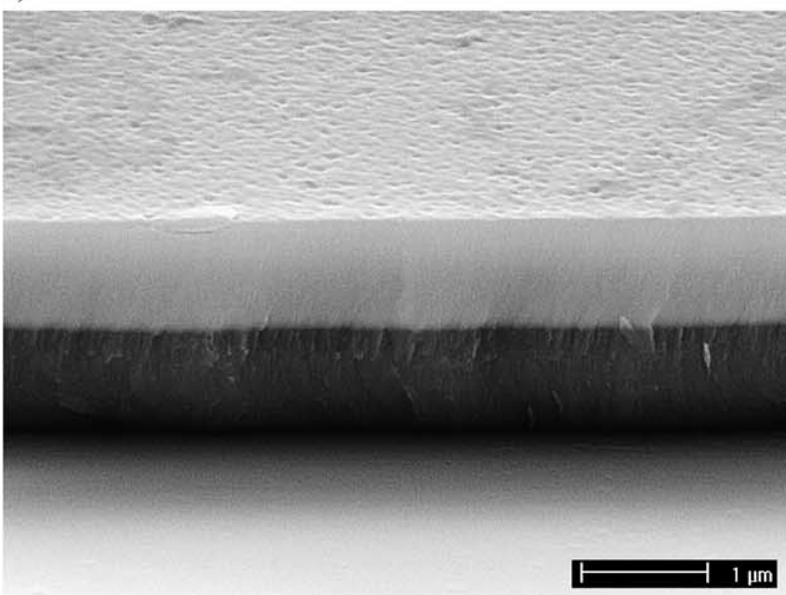

Fig. 5. Cross-sectional SEM micrographs of W-S-C sputtered films deposited with a $\mathrm{Ti}$ interlayer and with increasing $\mathrm{C}$ contents, showing the improvement of the morphology density: (a) $\mathrm{Ti} / \mathrm{W}_{35} \mathrm{~S}_{65}$ film, (b) $\mathrm{Ti} /$ $\mathrm{W}_{33} \mathrm{~S}_{54} \mathrm{C}_{13}$ film and (c) $\mathrm{Ti} / \mathrm{W}_{18} \mathrm{~S}_{18} \mathrm{C}_{64}$ film.

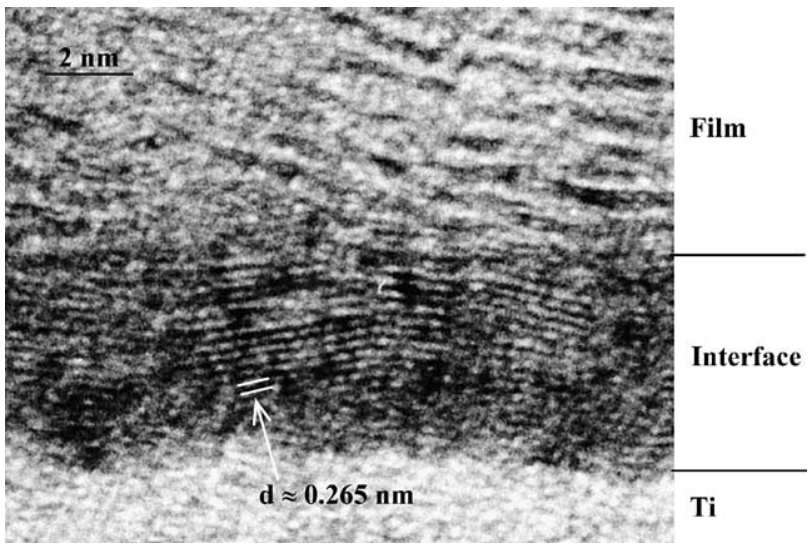

Fig. 6. Cross-sectional TEM micrograph from the interface between the $\mathrm{W}_{34} \mathrm{~S}_{50} \mathrm{C}_{16}$ film and the $\mathrm{Ti}$ interlayer showing the presence of the crystallographic plans of the $\mathrm{TiC}$ phase.

the (111) planes of TiC phase [20]. For N-containing films, a TiN phase was also observed in this interfacial region.

\section{Discussion}

The utilisation of cross-sectional electron microscopy techniques permitted the characterisation of the structure and morphology of the W-S-C(N) films, with regard to their alloying to carbon and nitrogen. Additionally, a further understanding of their mechanical and tribological behaviour was attained. The presence at the interface of grains oriented with the (002) plans normal to the substrate has been considered by Bertrand [3] to be due to the reaction of $\mathrm{S}$ atoms with the active places of the substrate surface, thereby forcing the perpendicular orientation of the crystallites. Moreover, Buck [21,22] referred that such places could be related to impurity contamination, such as oxygen that is always present in the film growth. If the presence of impurities determines type I growth, their effect is not only restricted to the interface but will extend onto the growth of the entire film, allowing the explanation of the progressive loss of grains with the orientation type II oriented far from the interface. The addition of carbon or nitrogen to W-S films further enhances the effect attributed to the impurities. The alloying atoms promote the formation of crystallites whose orientations will dependent on the directionality of the S dangling bonds. Consequently, textures with the (002) plans perpendicular or parallel to the substrate surface are less feasible and nanometer randomly oriented grains can be formed. The typical lamellar aspect of the W-S film becomes less evident and a more compact morphology is observed. The hardness of W-S films alloyed with $\mathrm{C}$ or $\mathrm{N}$ shows important improvements reaching values close to 6 GPa. This behaviour should be related to the changes of the morphology and the structure, where existing pores in the columnar morphology have been eliminated and the compactness and density of the films were improved. Moreover, a decrease of the grain size occurred, which 
associated with the emergence of new carbide/nitride phases, intrinsically harder than W-disulphide, gave rise to nanostructured materials and in some cases with a nanocomposite structure.

Rai et al. [23] have also showed hardness improvements of $\mathrm{WS}_{2}$ films up to $5 \mathrm{GPa}$ after irradiation by $\mathrm{Ag}^{+}$ions. They suggested that the main reason for the increase in hardness was the higher compactness of the films induced by the bombardment. Voevodin et al. [24], developed pioneering films of W-S-C with high $\mathrm{C}$ contents deposited by MSPLD (Magnetron Sputtering Pulsed Laser Deposition) and have reached hardness values of the order of 7-8 $\mathrm{GPa}$ in film containing $40-50$ at.\% C. They suggested the existence of a nanocomposite structure consisting of $\mathrm{WC} /$ $\mathrm{DLC} / \mathrm{WS}_{2}$. These hardness values were neither comparable to W-C carbides (24-28 GPa) nor to WC/DLC composites $(15-17 \mathrm{GPa})[25,26]$, but were significantly higher than the typical hardness of solid lubricants such as $\mathrm{WS}_{2}$.

The deposition of the Ti interlayer led to an increase of the adhesion of the coatings, which was only significant whenever they were deposited in a reactive mode with high relative flow of the reactive gas, i.e., higher critical loads were only measured if the W-S film incorporated high contents of $\mathrm{C}$ or $\mathrm{N}$. The following two factors are thought to contribute for this improvement: first, the formation of a transition layer of $\mathrm{TiC}$ or $\mathrm{TiN}$ between the $\mathrm{Ti}$ interlayer and the film, as observed in Fig. 6, creating an interface zone of high cohesion. The formation of this transition layer was confirmed by XRD results. Fig. 1 shows the XRD patterns of the $\mathrm{W}_{17} \mathrm{~S}_{15} \mathrm{C}_{68}$ and $\mathrm{W}_{34} \mathrm{~S}_{34} \mathrm{~N}_{32}$ films deposited with a Ti interlayer and registered in glancing and $\theta-2 \theta$ modes. In $\theta-$ $2 \theta$ mode, a couple of extra peaks are observed, which are related to the Ti interlayer and can be indexed as Ti and fcc TiN [27] or TiC [20] phases. Second, the grain orientations close the interface of films deposited with low alloy content is of concern. As referred previously, in the first layers most of the grains have their basal planes parallel to the substrate surface with only a few being observed perpendicular to the interface (see Fig. 2). The adjacent layers are held by weak van der Waals forces and therefore the propagation of any crack parallel to the substrate surface should be easier in type II than in type I films. With increasing alloying, stronger bonds arise because more grains are oriented with the basal planes nonparallel to the substrate (see Fig. 3). Additionally, the decrease of pore density promotes bonding between the W-S-C(N) film and the Ti interlayer. The tangential shear forces created at the interface that could lead to debonding of the coatings are thus more efficiently supported in the cases where either the basal $\mathrm{WS}_{2}$ planes are nonparallel to the interface or higher number of bonds is established between the film and the interlayer.

The HRTEM micrograph in Fig. 4 shows that it is possible to reach a nanocomposite structure in the alloyed films. The contrast observed suggests the possibility of agglomeration of atoms of different atomic weight, where the lighter zones are thought to be attributed to C-rich phases whereas the darker ones to tungsten carbide or tungsten disulphide. The good wear resistance exhibited by these films in combination with low values of the friction coefficient can be due to the presence of the carbon phase, which is known to behave well in humid atmospheres in contrast to $\mathrm{MS}_{2}$ films.

Finally, it is important to mention the excellent tribological performance of the W-S-N amorphous film in dry environments. The first studies on self-lubricating films of TMDC type referred the necessity of having films with a crystalline structure, i.e. (002) orientation, for achieving the low friction coefficient $[3,28,29]$, which was not the case in the present work. Others who focused on the doping of Mo$\mathrm{S}$ films with $\mathrm{Ti}[10,30]$, have also reached nanocrystalline/ amorphous structures and were able to maintain the friction coefficients at very low values. The film adapts itself during contact forcing the small crystallites to take an orientation where their basal planes are parallel to the contact, and thereby attaining low friction values [31]. Another possibility, in the case of an amorphous material [7] and [32 and references therein], is that the contact load leads to the local crystallization of the material and, therefore, creates an environment for low friction conditions.

\section{Conclusions}

HRTEM and HRSEM analyses of W-S films alloyed with $\mathrm{C}$ or $\mathrm{N}$ contributed to the understanding of the mechanical and tribological behaviour. The increase of hardness can be attributed to either the densification obtained in alloyed films or the formation of new intrinsically harder nanocrystalline phases, such as tungsten carbide or nitride. The adhesion improvement of W-S-C(N) films through the deposition of a Ti interlayer is only effective if accompanied by increased contents of $\mathrm{C}$ or $\mathrm{N}$. This is due to the formation of a TiC or TiN phases between the film and the Ti interlayer, respectively. The new phase induces a change from the (001) preferential orientation to a randomly orientation in the WS $\times$ crystallites close to the interface, or the occurrence of both situations simultaneously. The low wear and friction coefficients obtained in $\mathrm{C}(\mathrm{N})$ alloyed W-S films are essentially due to the increase of the adhesion and hardness of the films. In moist atmospheres, the C-alloyed films have better tribological behaviour, due to the presence of the amorphous carbon phase. These films are constituted by W-S, W-C grains and amorphous carbon. The films alloyed with high content of nitrogen are amorphous.

\section{Acknowledgement}

The authors would like to express their gratitude to Fundação Calouste Gulbenkian for a grant to Ana Nossa. Financial support through ECOSTAMP (EU) and POCTI/ EME/46548/2002 (FCT) projects are acknowledged. 


\section{References}

[1] B. Bhushan, B.K. Gupta, Handbook of Tribology-Materials, Coatings, and Surface Treatments, McGraw-Hill Inc., USA, 1991, p. 51.

[2] R. Bichsel, P. Buffat, F. Lévy, J. Phys., D. Appl. Phys. 19 (1986) 1575.

[3] P.A. Bertrand, J. Mater. Res. 4 (1) (1989 (Jan/Feb)) 180.

[4] S.V. Prasad, J.S. Zabinski, N.T. McDevitt, Tribol. Trans. 38 (1) (1995) 57.

[5] Da-Yung Wang, Chi-Lung Chang, Wei-Yu Ho, Surf. Coat. Technol. 111 (1999) 123.

[6] V. Buck, Vacuum 36 (1986) 89.

[7] M.R. Hilton, R. Bauer, P.D. Fleischauer, Thin Solid Films 188 (1990) 219.

[8] M.R. Hilton, Surf. Coat. Technol. 68/69 (1994) 407.

[9] M.R. Hilton, G. Jayaram, L.D. Marks, J. Mater. Res. 13 (4) (1998) 1022.

[10] N.M. Renevier, V.C. Fox, D.G. Teer, J. Hampshire, Surf. Coat. Technol. 127 (2000) 24

[11] Y.L. Su, W.H. Kao, Tribol. Int. 36 (2003) 11.

[12] S. Watanabe, J. Noshiro, S. Miyake, Surf. Coat. Technol. 183 (2004) 347.

[13] A. Nossa, A. Cavaleiro, Surf. Coat. Technol. 163/164 (2003) 552.

[14] A. Nossa, A. Cavaleiro, Mat. Sci. Forum 455/456 (2004) 515.

[15] A. Nossa, A. Cavaleiro, J. Mater. Res. 19 (8) (2004) 2356.

[16] N.J.M. Carvalho, J.T.M. De Hosson, J. Mater. Res. 16 (2001) 2213.
[17] M. Regula, C. Ballif, J. Moser, F. Lévy, Thin Solid Films 280 (1996) 67.

[18] J. Moser, H. Liao, F. Lévy, J. Phys., D. Appl. Phys. 23 (1990) 624.

[19] J.A. Thornton, J. Vac. Sci. Technol., A, Vac. Surf. Films 11 (4) (1974 (July/Aug.)) 666.

[20] International Center for Diffraction Data (ICDD), Pennsylvania, Cards 74-1219.

[21] V. Buck, Thin Solid Films 139 (1986) 157.

[22] V. Buck, Wear 114 (1987) 263.

[23] A.K. Rai, R.S. Bhattacharya, J.S. Zabinski, K. Miyoshi, Surf. Coat. Technol. 92 (1997) 120.

[24] A.A. Voevodin, J.P. O’Neill, J.S. Zabinski, Tribol. Lett. 6 (1999) 75.

[25] A.A. Voevodin, J.P. O’Neil, J.S. Zabinski, Thin Solid Films 342 (1999) 194

[26] A.A. Voevodin, J.P. O’Neil, S.V. Prasad, J.S. Zabinski, J. Vac. Sci. Technol., A, Vac. Surf. Films 17 (3) (1999) 986.

[27] International Center for Diffraction Data (ICDD), Pensylvania, Cards 71-0299.

[28] M.R. Hilton, P.D. Fleischauer, J. Mater. Res. 5 (2) (1990) 406.

[29] S.V. Prasad, J.S. Zabinski, Nature 387 (1997) 761.

[30] Da-Yung Wang, Chi-Lung Chang, Zie-Yih Chen, Wei-Yu Ho, Surf. Coat. Technol. 120/121 (1999) 629.

[31] J. Moser, F. Lévy, Thin Solid Films 228 (1993) 257.

[32] A. Ramalho, S. Fayeulle, M.T. Vieira, Thin Solid Films 253 (1995) 131. 